\title{
Figuring the Shame of Corruption in Jordanian Sociopolitical Discourse through a Range of Creative Metaphorical Scenarios
}

\author{
Mohammad Abedltif Albtoush ${ }^{1} \&$ Sakina Suffian Sahuri ${ }^{1}$ \\ ${ }^{1}$ Department of English Language, Faculty of Languages and Linguistics, University of Malaya, Malaysia \\ Correspondence: Mohammad Abedltif Albtoush, Faculty of Languages and Linguistics, University of Malaya, \\ Malaysia. E-mail: Mohammad_albtoush76@yahoo.com
}

Received: July 6, 2017 Accepted: July 26, 2017 Online Published: August 9, 2017

doi:10.5539/ells.v7n3p17 URL: http://doi.org/10.5539/ells.v7n3p17

\begin{abstract}
Using the tenets of the Cognitive Metaphor Theory (CMT) and the pragmatic approach of the Critical Metaphor Analysis (CMA), this paper investigates a variety of novel metaphoric scenarios targeting the conceptualization of the abstract concept of corruption in Jordanian sociopolitical discourse. My central argument is that by employing a range of conceptual domains to elicit a strong visceral reaction in his readership, the columnist Ahmad Hasan Al-Zu'bi connects the conceptual domain of CORRUPTION back to the equally abstract (but also deeply felt) conceptual domain of SHAME as the embedded running theme in the data under investigation. Unlike the corresponding model, which is primarily concerned with mapping elements from the source domain onto the target counterpart, these scenarios provide us with mini-narratives or storylines, shedding more light on the concept of SHAME which is crystallized through the diverse source domains utilized in the columnist's writings. The study is based on the analysis of 19 extracts taken from the writings of a popular Jordanian columnist Ahmad Hasan Al-Zu'bi in his well-known website Sawalief.com. Two main research questions are raised in this paper: 1 . What types of creative metaphoric scenarios are used to frame the abstract target concept of corruption? 2. Why are these particular creative metaphors exploited in the conceptualization of the problem of corruption? Findings of the study reveal that the creative power of these metaphoric scenarios does highlight and connect back to a powerful and emotionally resonant emotion that is important in traditional Jordanian society: SHAME.
\end{abstract}

Keywords: creative metaphoric scenarios, corruption, shame, sociopolitical discourse, Jordan

\section{Introduction}

The phenomenon of corruption has been considered an alarming sociopolitical issue in Jordan ever since 2010. More specifically, the years from 2010 until present are regarded as a critical period in the history of the Jordanian state, owing to the problem of corruption, which has patently left its marks on the country as well as on the Jordanian people. Apart from being the central issue addressed by various Jordanian mass media, this problem has become a popular topic in daily life as well. Its harsh impacts have led to growing strikes and demonstrations on the part of those Jordanians who are thirsty for social equity, the just life, and overall reform. In the light of this brief synopsis, the issue of corruption has been extensively addressed by the most popular Jordanian columnist Ahmad Hasan Al Zu'bi in his well-known website Sawalief.com, whereby he utilizes diverse metaphorical expressions in the depiction of this abstract concept of corruption. This is a satirical sociopolitical website which is mainly concerned with addressing local sociopolitical issues and regional ones in the Arab world. Reference is made to this website in particular because of the prominent position it gains among others in the Jordanian media. Indeed, the columnist's articles are prompted by higher readership in comparison to other columnists, and he weekly posts stand-up shows on YouTube as well as on other Jordanian TV channels such as Ro' $y a$. Moreover, owing to his creative writings, $\mathrm{Al} \mathrm{Zu}$ 'bi has been awarded and honored by many reputable institutions. For example, in December, 2015, he received an award that ranked him the most outstanding columnist in the whole Arab world.

Following (Musolff's, 2006) notion of scenario, this paper seeks to investigate the various metaphoric scenarios used in the portrayal of corruption in an attempt to see how these mini-narratives facilitate and simplify our understanding of this inaccessible, poorly delineated concept within the framework of the conceptual metaphor theory (CMT) by Lakoff (1980). According to (Semino, 2008) a scenario is defined as one type of mental 
representation whereby we have a bulk of information and knowledge about a particular experience in terms of its setting, goals, participants, entities and so on, with the result of providing us with ample specific details about the target concept through mapping the experiential aspects of the source domain onto the target counterpart. In addition, the paper also seeks to critically investigate the rhetorical function served by the metaphors under investigation.

In their seminal book Metaphors we Live By, (Lakoff, 1980; Lakoff \& Johnson, 1999, 2003) have emphasized that the omnipresence of metaphor is not only a parasitic phenomenon on our daily language per se. They argue that it is also a fundamental aspect of our thoughts and actions. In other words, defining our mundane realities, actions and behaviors is intrinsically conditioned by our conceptual system which is naturally metaphor-based. As a matter of fact, most current metaphor studies are carried out within the analytical framework of the CMT due to its aptness in terms analyzing metaphor on basis of linguistic versus conceptual metaphors. In short, the CMT holds as the most powerful and leading theory in the field of cognitive linguistics.

The columnist's metaphorical expressions serve as negative representation and evaluation devices for the phenomenon of corruption. Therefore, the agenda behind employing these linguistic metaphors are meant to convey how SHAMEFUL this problem is and how urgent it is to eliminate it. So far, studying the phenomenon of metaphor in Arabic language within scenario frameworks as well as critical metaphor analysis has not been given any attention when compared with that in other languages. For example, metaphor has been investigated in English (Howe, 1988; Lakoff, 2001; Lakoff \& Johnson, 2003; Mio, 1996; Musolff, 2004). It has also been examined in Spanish (Hellín García, 2009), (Jaworska, 2011) and in German, just to mention a few. Accordingly, the contribution of this research aims at crystalizing the concept of SHAME through the analysis of a set of novel metaphoric scenarios utilized in the depiction of corruption whereby these metaphoric scenarios mirror people's cultural experiences, human bodily experiences and the cultural belief system of the Jordanian community. To achieve this, two main research questions are posed:

(1) What types of metaphoric scenarios are used to frame the problem of corruption in online news column's discourse?

(2) Why are these particular creative metaphors exploited in the conceptualization of the problem of corruption?

Having introduced a brief background discussion of the notion of corruption, a rationale for the columnist whose writings are under investigation and an overview on the phenomenon of metaphor that is used to shape this abstract concept of corruption in the introductory section, section 2 is devoted to reviewing related literature on metaphor. Section 3 presents the theoretical framework within which the data is handled along with the methodology for analyzing the data. Discussion of analysis and results of the study will be presented in section 4 . Finally, section 5 will close the study with conclusion and recommendations for further research.

\section{Literature Review}

The notion of metaphor is a classic topic of investigation. Its origin dates back to ancient Greek, where it has received much interest since Aristotle. The Greek word for metaphor is "metapherin" in which the first part meta means "with" or "after" and the second part pherein means "carry" or "bear" following (Charteris-Black, 2004). This means that metaphor is a way of transmitting meanings from one semantic domain to another. Likewise, metaphor is defined in Merriam Webster Dictionary as "a figure of speech in which a word or phrase literally denoting one kind of object or idea is used in place of another to suggest a likeness or analogy between them".

However, metaphor was first depicted by classical theories as a deviant form of language (Goatly, 1997; Murray \& Rosamund, 2006). It was regarded as a decorative stylistic device of language, the linguistic equivalent of a garment for human body. Describing metaphor as such implies that it is something superfluous, an unusual means of using a language. In fact, this depiction is in stark contrast with the main tenet stressed by (Lakoff, 1980; Lakoff, 2001, 2003; Lakoff \& Johnson, 1999) in their landmark theory of the CMT, in the sense that metaphor is first and foremost a matter of cognition and only derivatively a linguistic feature. According to (Lakoff \& Johnson, 2003), "the essence of metaphor is understanding and experiencing one kind of thing in terms of another". Building on this proposition, a proper definition of metaphor holds as a cross-domain mapping, whereby the underlying cognitive materials and attributes of the concrete source domain are partially projected onto the imperceptible target one, enabling us eventually to reason about this host domain (Lakoff, 1980; Lakoff \& Turner, 1989). For example, the well-known conceptual metaphor LOVE IS A JOURNEY (Lakoff, 1980) shows how our familiarity and knowledge about the tangible, well delineated domain of JOURNEY helps to better capture the abstract, poorly delineated domain of LOVE. The attributes of the source domain are mapped onto the target counterpart such that lovers are conceived of as travelers. The love relationship is perceived in terms of the vehicle used in the journey. The goals to be reached by lovers are 
reasoned about in terms of the destination of the journey, and finally difficulties encountered by lovers are perceived in terms of obstacles met by travelers. The upshot behind these cross-domain projections is that metaphor is a means to both cognitively and semantically bridge the gap between two disparate concepts so that what is dissimilar eventually turns out to be similar.

By the same token (Semino, 2008) argues that metaphors "can provide ways of simplifying complexities and making abstractions accessible". In the political sphere for example (García, 2009) shows how the abstract concept of TERRORISM is framed via the concrete source domain of FIGHTING in the speech of the Spanish president. This conceptualization implies that terrorism is personified as an enemy whereby two fronts are met in a battle field scenario. More importantly, the president's use of linguistic metaphors belonging to the domain of FIGHTING performs three concurrent discourse functions: cognitive in the sense that he used metaphoric expressions belonging to the concept of FIGHTING, rhetorical in terms of personifying terrorism as if it were an enemy and thus evoking peoples' desire to beat it, and lastly ideological in that the president transmits his anti-terrorism agenda in a peaceful manner to get people's appeasement. It is apparent that metaphor choice is a powerful communicative weapon employed by language users and is never a value-free device haphazardly exploited in a given discourse.

In a similar vein (Charteris-Black, 2004) reports on political leaders' use of metaphors to portray different conceptualizations of the notion of terrorism in their speech. For example, Margaret Thatcher depicts terrorism as FIGHTING while Tony Blair frames it in terms of an EVIL. What matters in this juncture is that the abstract notion of terrorism comes to partake in the rhetorical agendas of language users.

In the field of economy (Rajandran, 2013) has carried out a study on the metaphorical language used in the Malaysian prime minister's speech in describing the Economic Transportation Program (ETP). As is the case with the notion of terrorism above, the concept of economy is also abstract. Consequently, the study reveals both the cognitive as well as the rhetorical functions behind the prime minister's choice of metaphors in his speech. For instance, at the cognitive level, the metaphoric expressions investigated in the corpus data are surface linguistic manifestations of underlying conceptual metaphors. The ETP is conceptualized in terms of PLANT, VEHICLE, JOURNEY and UP IS GOOD, all of which convey positive evaluations and successive development. At the rhetorical level, on the other hand, the particular choice of metaphorical expressions in the prime minister's speech conceals a hidden agenda: getting his government re-elected in the future.

Musolff (2006) argues that studying source domains should be anchored in analyzing the scenarios of these domains, owing to the fact that such scenarios enhance evaluative and attitudinal attributes relevant to the discourse community in question. Moreover, scenarios of (Musolff, 2006) comprise a rich ontological structure in terms of relevant attributes of basic domains as well as human beliefs, perceptions, goals and actions towards these attributes. This means that peoples' perceptions of the properties' basic domains are those sensed when projected onto target domains as if they were a storyline. In his analysis of the metaphorical language of public discourse, Musolff (2006) shows how the LOVE-MARRIAGE-FAMILY scenario is mapped into members of the European Union (EU). The storyline through which the (EU) is conceptualized proceeds in the same fashion as having a family in the sense that the relationship proceeds from flirting to engagement, marriage, having children, marriage problems and finally divorce. Rhetorically speaking, the male-centeredness bias for the German and British mirrors a patriarchal tradition of their culture that lurks behind this metaphoric scene.

Furthermore, Jaworska (2011) explores how the BODY-ILLNESS-CURE scenario is projected on imperceptible political issues. The Germans were considered as the host body for the Polish people who are a minority and are thus described as the foreign body causing illness to the German state. Therefore, the cure for such an illness is either to Germanize the Poles or to eradicate them. In short, the scenario carries the ethnic ideology of the Germans toward the Polish people whereby this tendency is pretty much like their anti-Semitic ideology towards the JEWS who are farmed as PARASITE within the biology or medical field.

The cognitive metaphor theory has so far proved its powerfulness and universality in all languages. In Arabic discourse for example, Torlakova (2014) applies the principles of the CMT on the abstract notion of the Arab Spring and explicates how it is made palpable via the metaphorical language investigated in her corpus data. Apart from the communicative function of metaphors, she has found out that they perform evaluative functions of the happenings in Tunisia. More specifically, these metaphors reflect cultural and Islamic traditions as well as general human experiences. Considering the brief literature review above, it is apparent that metaphor is an effective discourse strategy utilized by language users in many societies in order to communicate their intended goals — often subconsciously — to discourse recipients. 


\section{Theoretical Framework and Methodology}

This article combines two metaphor theories that are considered landmarks in the field of cognitive linguistics and critical discourse studies -the CMT and the CMA. This is because the former is an adequate analytical framework within which linguistic metaphors are made distinct from their conceptual counterparts and the latter has the potential of elucidating the pragmatic and discourse functions behind metaphor choice. The CMT is a cognitive approach developed by (Lakoff, 1980) in the seminal book Metaphors We Live By (1980). The basic tenet of the theory is that our perception of the world is intimately mirrored in our thoughts, which are shaped by metaphors. As the title of (Lakoff's, 1980) book suggests, reasoning about the world we live in stems from the metaphors that we use in our daily life.

Moreover, Kövecses (2005) has asserted that metaphor has cross-cultural and intra-cultural dimensions. Accordingly, every culture has its own way of conceptualizing the addressed target topic. Both Lakoff (1980) and Kövecses (2005) have emphasized that conceptual metaphors are also outcomes of human embodied experiences owing to universal human physiology and bodily experiences, such as emotions and diseases, despite the differences that may hold among cultures. However, Charteris-Black (2004) argues that though a powerful theory in the field of cognitive linguistics, the CMT suffers certain problems in that the examples provided by Lakoff and Johnson are invented and not contextually attested. There should be a complementary theory of context like critical metaphor analysis whose main task is to argue for the occurrence of metaphoric expressions in any given discourse, making them ultimately persuasive to discourse recipients.

The CMA is a pragmatic approach, reflecting the fact that context is a key factor influencing the meanings of metaphors. Charteris-Black maintains that the CMA is an integrationist approach whereby linguistic, semantic, cognitive and pragmatic criteria are involved. This indicates that since metaphor has various aspects that its explanation in a given discourse cannot be accounted for by just one criterion. Metaphor analysis within this model proceeds via three phases whereby each stage serves as a fodder to the next one: First, metaphor identification in which candidate linguistic metaphors and metaphor key words are identified. To do so, Charteris-Black introduced the notion of "semantic tension" as a proper defining strategy of linguistic metaphor in a given discourse. Building on this notion, Charteris-Black (2004) holds that metaphor is "a linguistic representation that results from the use of a word or phrase from the context or domain in which it is expected to occur to another context or domain where it is not expected to occur, thereby causing semantic tension". Within this phase, conceptual metaphors are inferred or generalized from their surface counterparts and if feasible conceptual keys are also inferred from the respective conceptual metaphors. Second, there is a metaphor interpretation phase, which is concerned with interpreting pragmatic or contextual meanings of metaphors by mapping elements from source-to target domain. Finally, there is the metaphor explanation phase, whose main concern is to reveal the purpose behind metaphor use in a certain context. This third stage has to do with the social role metaphor plays in a discourse in order to convey its persuasiveness to the addressees.

Methodologically, the study is mainly qualitative due to the exploratory nature of the questions pursued. The data source is taken from the columnist Ahmad Hasan Al-Zu'bi's well-known web site sawalief.com in the mainstream Jordanian newspaper alrai'. For this purpose, only data relevant to the abstract concept of corruption is selected. It should be pointed out the assembled metaphorical expressions are not only meant to make new meanings or explicate new ideas but also to perform a negative evaluation and representation of the SHAMEFUL problem of corruption and thus inspire the reader to accept the need for a solution. Indeed, Albtoush \& Sahuri (2017) have investigated the use of the predator/prey relationship in Zu'bi's writing as a rhetorical device designed to move the passive citizenry into action by shaming the Jordanian people into fighting corruption.

The corpus of the following study consists of 19 articles addressing the concept of corruption. Based on (Charteris-Black, 2004) notion of close reading technique, these 19 are articles are closely read and given much attention to identify the candidate linguistic metaphors. As in all metaphor studies, the style convention of metaphorical language followed in the present study is that metaphorical expressions are marked in italics, but capital letters hold for their respective conceptual counterparts. Metaphoric scenarios of the abstract target concept of corruption will be analyzed depending on the used basic domain in the data under investigation such as PUZZLING GAME, PATHOLOGY, and PHYSICAL DEFORMITY and so on.

\section{Analysis and Results}

The investigated data has revealed that the abstract concept of corruption is metaphorically conceptualized by the following concrete source domains: A PUZZLING GAME, A PATHOLOGY, A PHYSICAL DEFORMITY, AN ILLEGITIMATE PREGNANCY, DIRT, CRIME, A DIVERSION OF A LIFE-GIVING RESOURCE, A PEST, 
AN UNWANTED ANIMAL, DEFORMED FERTILITY, and BOUNDARY TRANSGRESSION. My central argument is that the novel metaphors under investigation connect back to the equally abstract concept of SHAME, which is nevertheless deeply felt in the traditions of the Jordanian community. Accordingly, the rhetoric behind these metaphors is a call to eradicate the scandalous issue of corruption. Let us first analyze the metaphoric scenarios of corruption within the domain of A PUZZLING GAME.

(1) Corruption is a sliding puzzle game (that you have to put together). A move to the right, a move to the left, pull up, pull down. We make great efforts to form the body of corruption. However, once we reach the last piece to complete the whole picture, all blocks get scattered and we have to start from scratch.

The italicized meta- metaphoric expression in (1) originates from our experience of the children's toy where children are given a $9 \times 9$ grid containing eight tiles and asked to slide them around to form an image. Corruption in this scene is framed in terms of a time-consuming game that keeps one busy putting these disassembled tiles together to form the correct image. Consequently, the conceptual metaphor: CORRUPTION IS A PUZZLING GAME is inferred. Indeed, the set-up of the scenario is projected from our experiences with forming a sliding puzzle game whereby its parts are scattered. We move one tile right, another left, still others are pulled up and down in order to come up with a complete image. However, once we reach the final step, the block of the image that we have successfully assembled is often ruined because the final tiles cannot easily be incorporated. At this point, we have to start over again. The crucial theme behind such a puzzling game is that it is boring and time-consuming. It is, in short, an UNPRODUCTIVE activity. Unproductiveness is closely associated with shame and, we shall see, a phenomenon often associated with corruption in this corpus of metaphors.

What makes this meta- metaphorical, though, is that it also provides a rationale for the use of metaphor to describe corruption in the first place. Corruption here is figured as a matter of complex relationships, highly dependent on being harmonized with its contexts. This constant moving back and forth to form the "picture" of corruption is precisely what $\mathrm{Zu}$ 'bi does through his writing and his liberal use of metaphors drawn from a diverse array of conceptual domains to create this complete "picture" of corruption.

Metaphoric expressions drawn from the source domain of PATHOLOGY, especially pathology blocking productive growth, appear to be the most frequently used. This has led to the inference that just as diseases are harmful and deadly to human beings and the flourishing of all living things, so too is corruption to the country. Moreover, the particular choice of disease metaphors such as the AIDS tend cluster together with other diseases that are considered particularly SHAMEFUL in the perceptions and traditions of the Jordanian community. It is no accident that many of these involve sex organs and activities associated with biological reproduction.

\section{BODY-ILLNESS SCENARIO}

Within the domain of PATHOLOGY, the target concept of corruption is framed in terms of illness in the body of the country. Therefore, we can deduce the conceptual metaphors: CORRUPTION IS AN ILLNESS and the COUNTRY IS A BODY or CONTAINER.

(2) Why do we ridicule others? Because the hemorrhoids of corruption, hemiplegia of handing down higher positions, the inflammations of favoritism, the pressure of mediation, the tumor of classism, the hernia of conscience, the disc of regionalism and the transmitted AIDS of individual interest that is transferred from the government to the parliamentary representatives- all these are the pains from which the country suffers.

It is patently seen that the italicized words draw from the pathology domain. Following (Charteris-Black, 2004) notion of semantic tension, the original occurrence of these words is not expected to occur in the context of depicting corruption, thereby they are metaphorically marked. According to (Lakoff, 1980; Lakoff \& Johnson, 2003), experiencing our bodies as CONTAINERS is one of the most fundamental and universal instincts of human beings. Therefore, the attributes of our bodily experiences of these illnesses are partially mapped onto the domain of the COUNTRY as if they were storyline or mini-narratives in the light of (Musolff, 2006) concept of scenario. Hemorrhoid is defined in Merriam Webster's Dictionary as one of the itchiest and most painful diseases that occurs either internally in the anal canal or externally around it causing eventually thrombosis. Therefore, it is associated with one of the most critical and shameful boundaries in human body in which it causes increased pressure in the veins, makes them swollen and keeps the patient in unbearable torment. In this metaphoric scenario, materials and aspects of this disease are carried over and projected onto the host body of the country that undergoes pains of corruption caused by corruptors. Big national companies and institutions of the country are critical locations for hosting corruption. Such mapping provides us with evidence for the conceptual metaphor CORRUPTION IS A SEVERE DISEASE. More significantly, from the Jordanian perceptive traditions, it is shameful for a patient who has such a disease to mention it in public as it is associated with the excretory functions of the human body and a region of the body that must remained covered at all times. Consequently, we 


\section{can infer a higher key conceptual metaphor: CORRUPTION IS SHAME}

By the same token, corruption in the above excerpt is realized by different forms of diseases such as hemiplegia, which is a paralysis in any part of human body due to an injury in the brain. This kind of disease when applied into the sociopolitical issue of corruption implies that higher positions in the government are confined to and handed down from father to son. In fact, the disease itself is widely understood to be inherited. Like other physical deformities, such paralysis is also considered shameful in traditional Jordanian culture, as are inherited diseases in general as they threaten the family's procreative potential. The other kinds of diseases are inflammations, pressure, tumor, hernia, disc and AIDS. Inflammations in medical texts imply an infective agent causing disease when hosting a body. Similarly, prolapsed disc is a painful disease which hinders people from normal movement, and AIDS is a serious disease of the immune system caused by infections with a virus. It is apparent that linguistic metaphors drawn from the pathology domain are clustering around each other in order to throw much light on the negative representation and evaluation of the corruption phenomenon. For example, AIDS as well as the other diseases are perceptually scandalous in the Jordanian traditions and more importantly they are figured as being caused by politicians and corrupters to the extent that they become chronic. The use of various types of diseases also complies with THE PUZZLING GAME conceptual metaphor in that the body of the state is overwhelmed by all these illnesses and rendered UNPRODUCTIVE, even STERILE.

Apart from the evaluative function, textual manifestations of metaphoric expressions are also realized by the notion of "recurrence" following (Cameron \& Stelma, 2004; Goatly, 1997) by which the different linguistic metaphors above draw from the only source domain of pathology. So, these concrete diseases do portray various forms of the SHAME of corruption such as cronyism, self-interest, nepotism, tribalism and so on. In pragmatic terms, the columnist's purpose is a call to eliminate all forms of corruption which are framed in terms of shameful creative metaphors peculiar to the Jordanian community.

(3) I address this message to the head of anti-corruption commission (Samih Beno) on the occasion of eliminating the malaria of corruption, typhoid of politics and cholera of robbery.

Again in example (3), corruption and its various forms are negatively shaped in terms of infectious and serious diseases exemplified by malaria, typhoid and cholera. In the excerpt above, the columnist ridicules the head of the anti-corruption commission because in actuality the commission has not eliminated the SHAMEFUL phenomenon of corruption. Indeed, this problem has become chronic and permeated in the state in which the corruptors are metaphorically conceived in terms of the biting mosquitoes that cause malaria and the country and citizens as their victims who demand medication and a cure. The attributes of these diseases are then mapped onto the body of the country in terms of its wealth and companies that are embezzled by corruptors. Likewise, the other diseases are serious and lead eventually to death if no action is taken immediately.

(4) "The free press (which usually stands with the country in its adversity and which incites it to heal from its pains and to overcome the fever of corrupters that occupies its body) will never be rewarded with death."

The country is perceived in terms of a body whose integrity has been compromised, leading it to experience harmful corruption. This association between CORRUPTION and the more latent key conceptual metaphors of BOUNDARY TRANSGRESSION and, ultimately, SHAME, are recurrent throughout the corpus. In the medical texts, fever disease keeps the patient unconscious and if the body temperature exceeds the normal limit, it leads to death. Human experiences with this disease are projected onto the country with the result that the citizens demonstrate every now and then questing reform. Consequently, the government's shame is attributed to its negligence in solving such a problem.

The abstract concept of corruption is also shaped in terms of diverse concrete entities that we live by. However, linguistic metaphors derived from their respective conceptual domains are less frequent in the data under investigation than those drawn from the conceptual domain of PATHOLOGY. To begin with, corruption is conceptualized in terms of DIRT, whereby this source domain is linguistically manifested in the following metaphoric expressions:

(5) We have heard more than one thousand times that the working governments will seriously fight corruption. However, we find out the filth of corruption is ubiquitous underneath their carpets as soon as they depart from authority.

(6) The government was delighted to change the head of the municipality because she wanted to clean the contamination of corruption.

(7) New governments should wipe out the spots of corruption which are left by the former ones using chemical detergents such as dettol soap. 
Linguistic metaphors in examples (5), (6) and (7) are surface realizations of the conceptual metaphor CORRUPTION IS DIRT. The metaphoric scenario here draws from our daily experiences of furnishing houses with carpets that need cleaning from time to time; otherwise they would become catching centers for collecting filth. In Jordanian society, it is shameful for one to have his/her home dirty in the presence of guests. Indeed, dirt itself is associated with shame. The anthropologist Mary Douglas famously defined dirt as "Matter out of place" (Douglas, 1966), highlighting the association between DIRT and BOUNDARY TRANSGRESSION, a theme that is deeply latent throughout the corpus. Ontologically, this scenario is carried over and applied onto the political domain in the sense that once a governmental cabinet departs from authority, their corruption becomes uncovered by the newly elected government. Likewise, in example (5), corruption is conceived of a contamination whereby the government shamefully insists upon maintaining it and consequently punishes whoever eradicates corruption by transferring her/him to another place. In example (7), however, the source concept of DIRT is sufficiently serious to require the use of chemical materials in eradicating germs through the use of an anti-bacterial soap often used on toilets and water circuits. In this scenario, people's houses correspond to the country's official institutions and national companies, and the filth that requires cleaning in these houses corresponds to the corruption that has infected the country's properties. The use of chemical detergents such as dettol soap indicate the shameful association of corruption to disgusting places where such cleaning agents are used, like toilets. Therefore, the use of the verb wipe out is associated with a call for immediate action just like cleaning dirt spots in our houses.

Metaphor scenarios for the conceptualization of corruption are also evoked by the source domain of ILLEGITIMATE PREGNANCY as exemplified in the metaphoric expressions in (8) below:

(8) Corruption in our country is, metaphorically speaking, an unmarried girl whose abdomen has swollen for nine months, with her parents indifferent toward her until she is due to give birth. At this point, the parents react in a jealous rage. For 25 years, corruption is getting wider and wider with no care on the part of the government to abort it.

In this metaphoric instance, corruption is framed in terms of ILLEGITIMATE PREGNANCY, which goes against both Islamic rules and Jordan's cultural and social value systems. The country corresponds to a girl, corruptors to those who seduce the girl and corruption is this unlawful outcome of the illegal marriage, hence we can infer the conceptual metaphor CORRUPTION IS SEDUCTION. The scenario, in this juncture, holds that the parents of the girl have observed their daughter's pregnancy since the time her abdomen began to get swollen until she delivered the bastard. For over the nine months of pregnancy, the parents were indifferent about this shameful and scandalous act, but when it is time to deliver the bastard, the parents were full of rage toward their daughter.

According to (Lakoff, 1980; Lakoff \& Johnson, 2003), personification is one type of ontological metaphor. The material of this source domain is analogically mapped onto the sociopolitical problem of corruption. The government has long observed how the country's wealth and national companies are embezzled apart from other various forms of corruption such as social injustice, cronyism and the like. However, instead of aborting the bastard in its early stages, the government has been indifferent about corruption until it reaches the climax, and thereby it is impossible to drastically eradicate this chronic phenomenon. Such a metaphoric scenario validates the proverb that reads as: prevention is better than cure. The metaphorical expressions above provide evidence for the following conceptualizations: CORRUPTION IS A BASTARD and CORRUPTION IS A SHAME or A SCANDAL. This is because committing scandalous acts as such is regarded as an everlasting stigma or slap on the face of the whole family.

Corruption is further depicted in terms of the conceptual domain of PESTS (9):

(9) We have appealed for a long time in our articles and everywhere that we strive to exterminate corruption and deprivation and get the siphoned money back to the country, but it turns out that all these attempts are useless.

By virtue of using the verb "exterminate", this example shows evidence of the conceptual metaphors: CORRUPTION IS A FIGHT and CORRUPTION IS AN ENEMY as in the relationship between humans and a pest that must be eliminated without mercy. Verbs are usually associated with a call for action. It appears that the personification of corruption as a pest implies that it can be physically identified just like corruptors. Nevertheless, public supplications to the government in annihilating corruption appear to be useless. Pests in need of extermination are shameful blemishes on the body and home of the person, further emphasizing the deep metaphorical association the columnist seeks to draw between CORRUPTION and BOUNDARY TRANSGRESSION and SHAME.

The semantic field of PLANTS is also inspired in depicting the corruption target topic as in the examples below: 
(10) There are tens of corruptors who are standing on the tree of corruption and siphoning the freedom of the country.

(11) All what we ask the government for is to eradicate corruption from its roots, bring the corruptors and interrogate them before justice.

(12) He who sows corruption must reap chaos.

These three metaphoric extracts show further evidence for the negative representation and evaluation of the complex concept of corruption with recourse to the domain of PLANTS. Though plants are usually associated with life and fruitfulness, these excerpts emphasize blocked or deformed fertility in the light of Charteris-Black's notion of "semantic tension", not unlike the example of ILLEGITIMATE PREGNANCY above. The italicized metaphoric expressions are expected to occur with the agricultural field, yet they are shifted to correspond to the sociopolitical issue of corruption. The conceptual metaphor implies CORRUPTION IS DEFORMED FERTILITY. In example (9), the tree in its basic context is big in size and rich in productivity, but in contextual sense it implies that lots of the country's properties that are embezzled by lots of corruptors, thus sapping its fertility and productive potential. Picking ripe fruit from trees corresponds to embezzlement of the country's wealth by corruptors. Example (10) conveys a public appeal and supplication so that the government could eliminate corruption. The choice of these metaphoric expressions derives from people's general experiences with farming in that protecting fruitful plants requires farmers to uproot neighboring harmful ones such as weeds, which represent DEFORMED FERTILITY. Example (11) depicts corruption as planting weeds or undesirable plants with the result of gaining an undesirable harvest. Ontologically, to keep on siphoning the country's wealth will inevitably lead to public dissatisfaction, demonstrations and internal riot. The above conceptual metaphor of DEFORMED FERTILITY is tied up with the higher key metaphorical patterns of the DIVERSION OF LIFE-GIVING RESOURCES and BOUNDARY TRANSGRESSION. Both of these in turn invoke the more abstract conceptual metaphor that CORRUPTION IS SHAME in that the government is shamefully indifferent and colluding with the corrupters' embezzlement of country's wealth.

The remaining source domains for the portrayal of corruption are derived from the semantic fields of UNWANTED ANIMAL, BOUNDARY TRANSGRESSION, CRIME, UNLIMITED HARMFUL RESOURCE, and finally PHYSICAL DEFORMITY.

(13) There are in front of you two options: either to sacrifice the corruption as an offering to the nation... or to favor corruption over the nation.

The words slaughter and sacrifice are associated with ANIMAL domain; hence their occurrence in this context causes semantic tension. The metaphoric scenario holds that corruption is depicted in terms of an unwanted animal that can be slaughtered instead of the priceless country. This implies that the country is the only resort and has priority over all considerations. The scenario is motivated by Islamic traditions whereby pilgrimage to Mecca requires the pilgrims to slaughter animals at the "Feast of the Sacrifice", owing to the prophet Ibrahim, who was ordered to sacrifice his cherished son Ismael, and was willing to do so, but Allah gave him a sheep instead (As Saffat Sura: verse 102). By analogy with this experiential scenario, eradicating corruption is a sign of cherishing, prioritizing and showing loyalty to the country. The other SHAMEFUL option is the government's siding with corruption with the result of ignoring the country, valuing an animal over the human community or, in extremis, even one's own son [Ismael], the most powerful symbol of potential fertility in Jordanian traditions. Killing one's son represents the greatest red line in traditional Jordanian society: the ultimate BOUNDARY TRANSGRESSION.

(14) We want to accomplish achievements; we do not want to spend a decade in corruption and another in anti-corruption.

(15) If a seismograph is used for measuring earthquakes, a barometer for atmospheric pressure, and a hygrometer for humidity in the air, then is not there "a corruption meter" -an instrument for measuring the rate of corruption in the body of the country? Or a "robbing meter" to detect robbing before its occurrence?

According to (Lakoff, 1980; Lakoff \& Johnson, 2003), the CONTAINER metaphor is a prototypical type of ontological metaphor and the most frequently used one in our everyday experiences. Moreover, Kövecses (2005) has stressed that most emotion metaphors are motivated by container image schema. In the example above, the target concept of CORRUPTION is conceived in terms of A SHAMEFUL CONTAINER image schema by virtue of the preposition in. Based on this, the people are the SUBSTANCE or interior and corruption is realized as this SHAMEFUL CONTAINER or exterior holding that substance. Spending a decade inside corruption implies that it covers a widespread area being seen to the observer. Likewise, the period of being inside this container 
indicates that it is deeply entrenched and rooted in the body of the country, compromising its integrity. Herein, there is a plea to get out of this bounded container as soon as possible before the body of the nation is further compromised and not to spend another ten years combating with this enemy.

The metaphoric scenario of CORRUPTION in example (15) is captured in terms of A NATURAL DISASTER such as an earthquake, a volcano, or a storm which can be predicted before hitting a region. Here, the columnist implicitly conveys a satiric scenario of corruption and compares it to a natural phenomenon. Apart from the negative representation of this problem, humorous effect is conveyed in the text in the sense that there should be a specialized instrument to measure the percentage of corruption in the country. This particular use of metaphor draws from educational learning experiences at schools about natural disasters and the specialized equipment that is designated for measuring each phenomenon. Thus, the percentage of corruption is so rife in the country with the result that its extermination appears to be a hurdle. More significantly, the columnist wishes to satirize corruption as a threat to the integrity of the body of the country, allowing something dangerous and destructive within it. As above, associating corruption with threats to the integrity of the body again suggests that corruption is SHAMEFUL and a form of BOUNDARY TRANSGRESSION. Furthermore, by calling for a device to measure and predict corruption, the columnist critiques the silence and lack of preventative action from the government's side towards the SHAMEFUL spread of corruption in the body of the country. The columnist challenges the Jordanian government and public to measure the SHAME of corruption with the same alacrity that it measures other potentially dangerous threats to the country like earthquakes and storms.

(16) The anti-corruption commission will seek a preventive detention for those suspects of corruption if they are thought to be in charge of the crime of corruption.

The semantic field of criminology is a further motivated domain for framing the target concept of corruption such as: CORRUPTION IS A CRIME. While corruption is often criminalized, it is not necessarily so and even criminal behaviors associated with corruption may not be perceived as such. Thus the equation of crime and corruption still produces a degree of semantic tension, although less than many of the previous examples. The italicized metaphoric expression of crime evokes a scenario whereby corruption is not a simple misdemeanor, but a highly SHAMEFUL felony committed by criminals who are set free of punishment. In here, participants of the scenario are the corruptors who are depicted as criminals or victimizer; the country and the public are the victims; the crime scene is the country's institutions and the SHAMEFUL felony is siphoning the money or the wealth of the country. More specifically, the columnist, in this extract, ridicules the notion that the anti-corruption commission will take immediate action against whoever thinks of committing this crime. Therefore, a humorous effect is created because in reality corruption has long been rife in the country and not treated as a crime, with the result that the anti-corruption commission is indifferent to it.

(17) What happened in the Arab world with respect to corruption is just mere slogans and not actions... We will fight corruption and dry its springs.

The theme of collusion is also recurrent in this excerpt in the sense that the governments' reaction to the corruption problem is confined to mere rhetoric rather than serious practical actions to eliminate it. According to Charteris-Black's notion of semantic tension, the linguistic metaphor springs has to do with natural resources of water that are associated with life and survival. However, its occurrence in this context implies harmful resources of corruption in terms of its agents (i.e., the corrupters). Building on this, the conceptual metaphor: CORRUPTION IS A DIVERSION OF A LIFE-GIVING RESOURCE can be inferred. In the light of (Lakoff \& Johnson, 2003) notion of "highlighting and hiding", it is the vast number of corrupters who are highlighted, owing to the large quantity of water in springs. In the Quran, there are a number of stories of peoples who lived in corruption and shame while benefiting from bountiful springs and water supplies, including the story of Lot (Arabic Lut) and the story of Aad and Thamud. Yet God punished these people for their shameful behavior by taking away their water, drying their springs and sending down brimstone. Thus the productive potential of water, which had been corrupted and turned to illegitimate ends by these communities, was thereafter denied to those who refused the advice of prophets to give up their wickedness and return to their duty of worshipping God.

(18) I cannot believe that corruption has suddenly become widespread on the face of the Jordanian state as if it were a pimple in teenage years and that it will inevitably disappear with an administrative diet. I am sure that corruption is inherent in our country.

(19) He who listens to the government's officials when justifying the causes behind corruption, the first thing coming into one's mind is that there is a jinni which beautifies corruption and causes problems.

Corruption is described in terms of a physical deformity as shown in examples (18) and (19). The metaphoric expression pimple is defined in medical texts as a small, red, swollen spots on the skin. Likewise, the verb 
beautifies, in the last excerpt implies that corruption is an ugly entity that needs cosmetics in order to look better. These linguistic metaphors provide evidence of the conceptual metaphor: CORRUPTION IS A PHYSICAL DEFORMITY. The country is personified as if it were a young man or woman and corruption corresponds to those widespread pimples over one's skin. The scenario evokes a sense of SHAME, because the appearance of one's "face" is symbolically loaded in Jordanian traditions. In fact, to cause permanent damage to the face of another person is a grave offence in tribal law, and natural facial deformities are sometimes believed to reflect on the moral character of the person in traditional Jordanian communities (Al-Abbadi, 2006). For a person to show up in public with such a deformity is humiliating and consequently the scene is carried over onto the country, which is figured by analogy as being distorted by corruption. What is more, pimples are first observed when looking at one's face because it is a crucial boundary between the human body and its social existence and perception. To have unsightly blemishes erupt across the boundary of the face represents a shameful form of BOUNDARY TRANSGRESSION. In the same vein, the country's companies and institutions can be represented as a face that can never be hidden. Example (19) shows us how Satan and his followers whisper to someone and make prohibited, SHAMEFUL acts look attractive in his/her eyes. By analogy, siphoning the country's wealth appears pleasant in the eyes of the corruptors - although this is only an illusion as deformity lurks beneath. Finally, metaphor choice is drawn from the Qura'nic context in which Satan plays a pivotal role in making boundary transgressions and other forms of wrongdoing look desirable to those whose faith is weak.

\section{Conclusion}

The analysis of the investigated data has shown that figuring out the abstract target concept of corruption in the Jordanian sociopolitical discourse draws from various semantic fields that are mainly represented by: A PUZZLING GAME, A PATHOLOGY, A PHYSICAL DEFORMITY, AN ILLEGITIMATE PREGNANCY, DIRT, CRIME, A DIVERSION OF A LIFE-GIVING RESOURCE, A PEST, AN UNWANTED ANIMAL, DEFORMED FERTILITY, and BOUNDARY TRANSGRESSION. However, what is more significant in this juncture is that all these metaphorical conceptual patterns highlight the embedded resonant emotion of SHAME which is particularly central to morality in Jordanian society. Consequently, based on Charteris-balck's notion of "metaphor hierarchy", the linguistic metaphors in the data examined are surface realizations of the above conceptual metaphorical patterns and those latter ones belong to the higher key conceptual metaphor of CORRUPTION IS SHAME. Moreover, the columnist's creative use of these metaphorical expressions can be facilitated through "scenarios" rather than Lakoff's "corresponding model" whereby the former have the potential to spin out the discourse traditions of the Jordanian community. This does not mean to downplay the role of the "corresponding model" in the conceptualization of corruption, rather it works as a platform for scenarios. Finally, as a recommendation for future research, it would be interesting to analyze the SHAME of LOCAL POLITICAL MALPRACTICE through the use various novel metaphorical scenarios.

\section{References}

Al-Abbadi, A. O. (2006). Bedouin Justice: The Customary Legal System of the Tribes and its Integration into the Framework of State Polity from 1921-1982. Amman: Dar Jareer.

Albtoush, M., \& Sahuri, S. (2017). Beyond Predator and Prey: Figuring Corruption through Animal Metaphoric Scenarios in the Jordanian Context. English Language and Literature Studies, 7(2), 110-119. https://doi.org/10.5539/ells.v7n2p110

Cameron, L. J., \& Stelma, J. H. (2004). Metaphor clusters in discourse. Journal of Applied Linguistics, 1(2). https://doi.org/10.1558/japl.2004.1.2.107

Cameron, L., \& Low, G. (1999). Researching and applying metaphor (Vol. 41). Cambridge: Cambridge University Press. https://doi.org/10.1017/CBO9781139524704

Charteris-Black, J. (2004). Corpus approaches to critical metaphor analysis. New York: Springer. https://doi.org/10.1057/9780230000612

Douglas, M. (1966). Purity and Danger. London: Routledge Press. https://doi.org/10.4324/9780203361832

Goatly, A. (1997). The Language of Metaphors: Literal Metaphorical. Taylor \& Francis US. https://doi.org/10.4324/9780203210000

Hellín, G., \& María, J. (2009). Fight metaphors in Spain's presidential speeches: JL Rodríguez Zapatero (2004-2007).

Howe, N. (1988). Metaphor in contemporary American political discourse. Metaphor and Symbol, 3(2), 87-104. http://dx.doi.org/10.1207/s15327868ms0302_2 
Jaworska, S. (2011). Anti-Slavic imagery in German radical nationalist discourse at the turn of the twentieth century: a prelude to Nazi ideology? Patterns of Prejudice, 45(5), 435-452. http://dx.doi.org/10.1080/0031322X.2011.624762

Kövecses, Z. (2005). Metaphor in culture: Universality and variation. Cambridge: Cambridge University Press. https://doi.org/10.1017/CBO9780511614408

Lakoff, G. (2001). Metaphors of terror. In These Times.

Lakoff, G. (2003). Metaphor and war, again. Alternet.

Lakoff, G., \& Johnson, M. (1999). Philosophy in the flesh: The embodied mind and its challenge to western thought. Basic books.

Lakoff, G., \& Johnson, M. (2003). Metaphors we live by. 1980. Chicago: U of Chicago P. https://doi.org/10.7208/chicago/9780226470993.001.0001

Lakoff, G., \& Mark, J. (1980). Metaphors We Live By. Chicago: University of Chicago Press.

Lakoff, G., \& Turner, M. (1989). More than cool reason: The power of poetic metaphor. Univ. of California at Berkeley, Berkeley. https://doi.org/10.7208/chicago/9780226470986.001.0001

Lakoff, J., \& Johnson, M. (1980). Metaphors we live by. Chicago: University of Chicago Press.

Mio, J. S. (1996). Metaphor, politics, and persuasion. Metaphor: Implications and Applications, 127-146.

Murray, K., \& Rosamund, M. (2006). Introducing metaphor. London/New York.

Musolff, A. (2004). Metaphor and political discourse. New Youk: Springer. https://doi.org/10.1057/9780230504516

Musolff, A. (2006). Metaphor scenarios in public discourse. Metaphor and Symbol, 21(1), 23-38. https://doi.org/10.1207/s15327868ms2101_2

Rajandran, K. (2013). Metaphors for Malaysia's Economic Transformation Programme. Kajian Malaysia, 31(2), 19.

Semino, E. (2008). Metaphor in discourse. Cambridge: Cambridge University Press.

Torlakova, L. (2014). Metaphors of the Arab Spring: Figurative construals of the uprisings and revolutions. Journal of Arabic And Islamic Studies, 14, 1-25.

\section{Copyrights}

Copyright for this article is retained by the author, with first publication rights granted to the journal.

This is an open-access article distributed under the terms and conditions of the Creative Commons Attribution license (http://creativecommons.org/licenses/by/4.0/). 